\title{
The Causes, Prevalence and Interventions for Dyscalculia in Malaysia
}

\author{
Mohammad Amimul Ihsan Aquil ${ }^{*}$ \\ Mazeyanti Mohd. Ariffin ${ }^{1}$ \\ ${ }^{1}$ Department of Computer and Information Sciences, \\ Universiti Teknologi Petronas, Malaysia \\ ${ }^{*}$ Corresponding Author
}

DOI: https://doi.org/10.36941/jesr-2020-0126

\begin{abstract}
Children with Dyscalculia show deficits in the basic understanding of quantities and numbers, which cause difficulties in math skills acquisition despite adequate schooling. This study summarizes the current knowledge regarding causes, diagnosis and treatment of Dyscalculia in Malyasia from a clinician's perspective. The findings reveal that Dyscalculia is a brain based specific learning disability, which often co-exist with other neurological disorders such as Dyslexia and attention-deficit hyperactive disorder (ADHD). Symptoms of Dyscalculia include difficulty in reading, writing, counting, arithmetic calculation, direction co-ordination, finger counting agnosia and time management. A computer-based Diagnosis of Dyscalculia should measure all the possible difficulties that are faced by Dyscalculic patient along with other disorders that might co-exist with Dyscalculia and IQ. Care can be provided to Dyscalculia children using one-on-one intervention and the implementation of a standard policy based on health professionals, teachers, parents for diagnosis and treatment. The study also shows the need for more research into the current situation, diagnosis and intervention of dyscalculic cases in Malaysia to help meet the needs of these dyscalculic children.
\end{abstract}

Keywords: Dyscalculia, Premature birth, etiology, SPLD

\section{Introduction}

Dyscalculia refers to specific learning disability which affects the ability to acquire arithmetical skills, comprehension of numerical mathematical problems and working with numbers (Gillium, 2012; Geary,2006). It has negative consequences for the children, youth and society at large. The prevalence rate of Dyscalculia ranges from 3 to 6.5\% (Shalev, 2011; Price \& Ansari, 2013) based on studies conducted in different countries, which makes it as common as Dyslexia (a learning disability which affects reading skills) and a high degree of comorbidity is observed between Dyslexia and Dyscalculia (Kaufmann, Aster; 2012). Often, Dyscalculia is described to be dependent upon and associated with multifactor abilities such as executive, memory, spatial and verbal functions. Research evidence has shown several causal factors associated with Dyscalculia and depend upon multifactor abilities, including executive, verbal, spatial and memory functions (Soares et al., 2018). It is remained unanswered which are the underlying cognitive deficits behind Dyscalculia, yet various factors have been proposed. From Education psychologist's perspective, major factors are widely discussed by researchers which are named number sense deficit hypothesis and access deficit hypothesis (Wong et al.,2015). First hypothesis proposes that deficit in processing non-symbolic numerosity is the origin of 
Dyscalculia and second hypothesis proposes that the core deficit of Dyscalculia is in the inefficient access of number symbols representation in terms of magnitude which is also knows as symbolic deficit. From neuropsychological and Epidemiological perspectives, Dyscalculia is brain-based disorder and argues that Dyscalculia is caused dysfunction of left and right brain hemispheres (luclano,2016) . Despite of different opinions regarding root causes of Dyscalculia in different disciplines, the diagnosis is still based of academic. Remediation of Dyscalculia includes classroom and ICT based interventions (Shalev, 2011; Soares et al., 2018) . The aim of this article is to give an overview of Dyscalculia based on Health professional's perspective and recent studies in order to raise awareness among educators regrading Dyscalculia students.

\section{Literature Review}

Literature informing the study was sourced from peer-reviewed journals such as the MEDline and PsychINFO databases. The terms used in the search include: "math disabled," "less skilled math," "math disabled/reading disabled," "problem solving in math," and "dyscalculia," among others.

\subsection{Definition}

Dyscalculia is a Specific Learning Disability whose name comes with a number of learning variations such as learning disability, learning difficulty, learning disorder or a learning difference. It also goes by other terms but those will not be included since they are inconsistently and poorly defined. The differences between these terminologies have been the cause of a number of challenges for readers looking to study the condition. According to the World Health Organization (WHO), Dyscalculia is a specific disorder in a human being that manifests itself in the form of deprived mathematical skills. Dyscalculia, is also defined by the Diagnostic and Statistical Manual (DSM-IV), as a mathematical disorder. The UK department for education and skills, on the other hand, remains solely fixated on the use of the term "dyscalculia."

Dowker's (2005) study denotes that even with research being done in the area focusing and talking of Dyscalculia as a mathematical difficulty, it would be appropriate to refer to it as an arithmetic difficulty. The field of mathematics is divided into different branches whereby arithmetic falls as a branch and a relatively unimportant one. Therefore, might lead to the proliferation of names caused by such situations creates ground for more confusion. It can also be noted that using various criteria, tests and exclusions make the investigation and comparison of Dyscalculia more complicated.

Most of the Malaysian-based research Define Dyscalculia as the inability to acquire arithmetic skills and comprehend the concept of numbers (Miyundy et al., 2019; Mazeyanti et al., 2018; Sarpudin \& Zambri, 2014; Zulkifli et al., 2012). (Wei et al., 2019) defined Dyscalculia as the arithmetic difficulties, computing capacity significantly lower than its intelligence, age and education level.

However, even in the light of the confusion arising from the wording used, all the definitions have a common denominator; they talk about a severe disability that impedes the ability of an individual to learn arithmetic.

\subsection{Characteristics of Dyscalculia}

Difficulties in mathematics in children can be caused by a myriad of factors, with Dyscalculia being one of them. Therefore, identifying the main reason for the mathematical difficulty is necessary. Even with a consensus lacking in the definition of Dyscalculia, researchers have come to a common agreement regarding its characteristics. The characteristics can be found in the Learning Support Services Booklet titled “what is Dyscalculia?" They include:

a) A deficiency in the primary aspect of number sense that is manifested by being unable to see things without counting (subitize), specifically in scenarios involving smaller quantities.

b) A poor number sense, which is related to number operations, number relations and whole 
numbers. Key examples would include an inability to tell which number is large out of two, experiencing difficulties in reliably counting numbers backwards and the inability to gauge and tell if a numerical answer is somewhat reasonable befitting the context.

c) Using fingers as a "counting on" strategies rather than relying on efficient calculation methods and confusing mathematical signs such as the addition and multiplication signs.

d) Inefficiencies exhibited in money management.

e) Problems with discerning the various time aspects. Such can be manifested in scenarios such as the inability to effectively manage time in day-to-day life and the inability to tell time from an analogue watch.

f) Issues related to memory. For example, an individual experiencing short-term and long-term memory weakness, directional and sequencing confusion in a way that one cannot tell between east and west, left and right, and difficulty in learning the mathematical tables.

When providing an insight into the best alternative strategies for dealing with dyscalculics, there is a need to consider various time aspects. That is, more time should be allowed for them to process calculations. Additionally, as noted by Butterworth (2003), such individuals will, therefore, need to be allowed more time when undertaking their examinations. This is because such individuals portray a poor sense of organization and elapsed time. Dyscalculics should, therefore, be furnished with digital clocks as they experience key challenges dealing with analogue ones (Williams, 2013).

\subsection{Causes of Dyscalculia}

Computation is very complex and demands the interaction of numerous brain functions. Children with a computational disorder show significantly reduced activity in the brain regions that belong to the neural network of quantity and number processing during the processing of simple computational tasks (Ashkenazi, Rosenberg-Lee, Tenison \& Menon, 2012; Kucian et al., 2006). This is probably the result of a genetic deficiency of congenital core competencies, which leads to certain cognitive functions not developing according to developmental tasks (Butterworth, 2005; von Aster et al., 2007). For example, the connection between an Arabic numeral ("8") and the corresponding set is usually activated automatically, which is not the case for a person with Dyscalculia (Rubinsten \& Henik, 2006). Numbers to them are like words without meaning. Other basic mathematical skills are also impaired in the case of computational error (Gaupp et al., 2004; Landerl et al., 2004; von Aster et al., 2005). These include the rapid (at a glance) counting of small quantities, the comparison of quantities (more/less) and numbers (larger/ smaller), the naming and writing down of numbers, as well as the development of a mental line of numbers. Deficits in general cognitive functions such as memory, processing speed, and visual-spatial functions, were also reported (Landerl \& Kaufmann, 2008). Family and twin studies indicate that Dyscalculia could be genetic (Alarcon, DeFries, Gillis Light \& Pennington, 1997; Docherty et al., 2010; Petrill et al., 2012; Shalev et al., 2001).

Studies on neurophysiological correlate using MRI, fMRI, and ERPs were able to identify brain regions that correlate with different computational processes (Vogel \& Ansari, 2012). The activation of the intraparietal Sulcus (IPS) of both hemispheres was found, for example, depending on the ability to detect numerical distances between numbers. The linguistic processing of numbers in computational operations, on the other hand, is associated with activation in the left gyrus angularis. Studies with children with Dyscalculia confirmed the importance of IPS for estimating and comparing amounts. Kucian et al. (2006) found lower activation in children with Dyscalculia is a numerical estimation task (EG $4+3=9$ or 6$)$. Further studies confirm the connection between lower IPS activation and basic numerical abilities (Kaufmann, Vogel et al., 2009; Price, Holloway, Räsänen, Vesterinen \& Ansari, 2007). Other basic mathematical skills are also impaired in the case of computational error which includes the rapid (at a glance) counting of small quantities, the comparison of quantities (more/less) and numbers (larger/ smaller), the naming and writing down of numbers, as well as the development of a mental line of numbers. Deficits in general cognitive functions such as memory, processing speed, and visual-spatial Functions, were also reported (Gaupp et al., 2004; Landerl et al., 2004; von Aster et 
al., 2005). Studies with children with Dyscalculia confirmed the importance of IPS for estimating and comparing numbers. Kucian et al. (2006) found lower activation in children with Dyscalculia for a numerical estimation task (e.g. $4+3=9$ or 6 ). Further studies confirm the connection between lower IPS activation and basic numerical abilities (Kaufmann, Vogel et al., 2009; Price, Holloway, Räsänen, Vesterinen \& Ansari, 2007).

\subsection{Dyscalculia Identification Methodology}

There are two key methods that one can use in conjunction with the stated paradigms to identify Dyscalculia. These include qualitative or quantitative methods. Qualitative methods are provided for under WHO, UK learning support services, DfES and the DSM-IV. The qualitative methods used, on the other hand, can rely on one of the three categories of the model. These include the discrepancy model, severity model and the "resistance to treatment" model. According to the discrepancy model, there exists a significant inconsistency in a child's performance in arithmetic compared to the overall performance/ achievements. The severity model relies upon cut off points such as percentiles to determine the condition's level of severity.

Lastly, the "resistance to treatment" is employed in scenarios where a child remains unresponsive to any implemented interventions and chooses to continue using immature arithmetic strategies rather than efficient ones. For example, the child might decide to go back to finger counting as they experience difficulties in remembering number bonds (Shalev \& von Aster, 2008). However, there is no explicit explanation of the followed method for Dyscalculia identification mentioned by Malaysian Dyscalculia researchers.

\subsection{Prevalence of Dyscalculia}

Dyscalculia's level of prevalence remains largely unknown. A study done by Butterworth (2002) shows that the total number of dyscalculia diagnosis remained at 5-6\%, while Geary (2004) places the number at a contradictory $8 \%$. With the study's statistics being drawn for children, the prevalence of Dyscalculia might be high as the whole chunk of adult learners are yet to be diagnosed or assessed. As people become more aware of Dyscalculia, the number of diagnoses is expected to increase. When it comes to data regarding the prevalence of the condition, there exists a wide range of data that highlights it and will mainly depend on the criteria utilised in the cutoffs and identification for determination. From the available research, it can be noted that data on prevalence shows a variation of about 3-7\% (Kauffman et al., 2012). When the same prevalence is compared in terms of gender, the results obtained have heavily relied on the criteria chosen for the identification and the accruing differences between the genders that might have been omitted under the relative discrepancy criteria and thresholds that are crucial in the definition of Dyscalculia (Soares et al., 2018). Interestingly, there lacks comprehensive research evidence that details the prevalence of Dyscalculia in the whole of Malaysia. According to Wong et al., (2014) pilot study conducted among 91 primary school pupils show that a total of $5.5 \%$ of school-going kids have exhibited Dyscalculia. Another study conducted by Miundy et al., (2019) in Selangor among 50 students of primary schools using Virtual Reality based system show Dyscalculia prevalence rate of $4 \%$. Keong's (2016) study further the research by showing that $4.38 \%$ of girls and $3.47 \%$ of boys in any settings are likely to suffer from Dyscalculia in Malaysia. Even with those studies being focused on an isolated case, they are helpful in revealing that some Malaysian children in school settings indeed exhibit Dyscalculia

\subsection{Comorbidity of Dyscalculia}

Dyscalculia and Dyslexia are two disorders that have considerable overlaps. For example, a number of studies have shown that Dyscalculia will occur more often in children compared to word blindness dyslexia. However, there is much that remains unknown about Dyscalculia regarding treatment, causes 
or prevalence (Diwan, 2008). Studies have noted that both disorders might occur at the same time affecting about 20-60\% of all students (Hannell, 2005). A study done by Orly \& Avishai, (2006) regarding the relationship between Dyscalculia and Dyslexia reveals that while Dyscalculics have issues with the association of numerals with magnitudes but no issue with connecting letters with their phenomes. Students with Dyslexia, on the other hand, exhibit. Another study conducted by Willburger et al, (2008) assessing the naming speeds in Dyscalculia and Dyslexia shows that the cognitive bases on Dyscalculia and Dyslexia are independent of each other.

According to Rani et al, (2014) Dyslexic students in Malaysia also exhibit a poor proficiency in mathematics due to their existing difficulties in writing and reading. Additionally, in addition to their learning ability, the common characteristics of these students such as memory deficits, visual difficulties and thinking styles are also affected by this cognitive defect (Rani, Rohizan, Rahman; 2014)).

\subsection{Diagnosis of dyscalculia}

Screening for dyscalculia can be done in a number of ways. The available screeners for dyscalculia were developed in regard to the researcher's discipline. For example, one key example of such a screener is one developed by Butterworth (2003). This is the most common commercial screener used across UK and is Also known as the Dyscalculia screener. This screener is based on the notion that dyscalculia is caused by a numerosity deficit. The screener relies on computer technology and takes about 20 minutes to finish the whole screening process. By using a item-timed calculation, this screener makes it easy for one to identify the finger counters from fluent counters. Butterworth's screener comprises of 4 main tests which include:

a) An arithmetic achievement test (multiplication and addition). This test helps the administer of the text distinguish children using strategies to record number facts or those who can do so without the intervention of any strategies.

b) The numerical stroop or number comparison. This helps point out dyscalculic children as they often experience a difficulty when doing a comparison between the magnitude of various numbers.

c) The dot enumeration test which acts as a measure of a child's ability to subsidize. A difficulty to subsidize is a key characteristic of dyscalculia.

d) The simple reaction time test: This test is crucial in giving an accurate estimate on the time taken by a child to give a response. A slow response time can signal a dyscalculic

Another screening method is the Von Ater \& Dellatolas 's (2006) ZAREKI-R screener which is comprised of 12 major subsets. These include Number comparisons, word problems, cognitive quantity assessment. Perceptive quantity assessment, number comparison, repeating numbers forwards and backwards, arranging numbers on a number line, reading numbers, mental arithmetic, writing numbers, counting backwards orally and counting.

The next screening method is the Number Sense Screener (NSS), a quantitative screener developed by Jordan (2012), a psychologist in an attempt to help with the identification of Dyscalculia. The basis of this screener is the notion that Dyscalculia results from the lack of a number sense. The NSS test by Jordan help identify a child's aspect of number sense. Jordan's screener involves the use of tests such as number combinations, story problems, nonverbal calculation, number comparison, number recognition and counting tests.

Another key screener is the Number Sets Test, which was developed by cognitive developmental psychologist Geary et al (2012). The main aim of this test is to carry out an assessment on the accuracy and speed that a child uses in identifying and processing any process that encompasses Arabic objects and numerals sets.

At the moment, Malaysia lacks a standardized instrument that can be used in the diagnosis of Dyscalculia. However, there have been a number of efforts towards the development of such an instrument made by Wong's et al., (2014 who named it as "Malaysian Dyscalculia instrument Plus" (MDI+). This screener is built on a computer system that measures four variables including Arithmetic, 
Numerosity, short term memory and simple reaction time. This screener is founded on Butterworth and Geary dyscalculia screeners and comprises of three tests. They include Arithmetic Test, Numerosity, short term

\section{Methods}

This study aimed to find challenges Dyscalculia students face in real life, their diagnosis and remedial measures. Qualitative approach was adopted with an interpretative case study in Malaysia. The study relied on two categories of research including semi structured interviews and literature based research. Semi-structured interviews were used as the main data-gathering device used for this study was semistructured interviews since it "is particularly good at enabling the researcher to learn, first hand, about people's perspectives on the subject chosen as the project focus" (Davies, 2007, p.29) in addition to their ability to capture the complexity and depth of the participants' experiences. By using semistructured interviews, the interviewer is likely to gain insight into the beliefs, attitudes, preferences and values of the study population. The method used was the 'convenience sampling method and carried out by contacting Health professionals via email.

\subsection{Data Collection \& Analysis}

The questions for semi-structured interview were prepared in such a way as that reveals the perception of doctors and special education teachers on dyscalculia. A special education teacher and a field expert were consulted for expert opinion in reviewing the draft form to be used for the study. With the approval of the expert, the draft for was used to conduct the pilot implementation and interviews. The final form had eight open-ended questions, which included:

1) In your own opinion, what is Dyscalculia? Please explain

2) What are the symptoms of Dyscalculia patient and how do you diagnose them?

3) What are the primary causes of Dyscalculia in your opinion in Malaysia?

4) In your opinion, what is the ideal age to conduct Dyscalculia Diagnosis?

5) Is there any Dyscalculia diagnosis instrument, guideline or best practice you would like to recommend for Dyscalculia diagnosis?

6) Is there any remedial measures you would like to recommend for Dyscalculia?

7) If you would like a computer program to assist you in diagnosing Dyscalculia, what are the features or component you would like to have?

8) Do you think a standard policy will be helpful for Dyscalculia children?

The study participants included 11 participants: 9 doctors (psychologists, psychiatrists and neuropsychologists), one education psychologist and a special education teacher. The interviews were done either face-to-face, phone or through zoom video. To ease data analysis, the interviews were audio-recorded while the key points of the focus group were noted on flip charts. This was important since all the researchers belonged to an academic faculty and having these checks helps highlight potential presuppositions of priority areas. The transcription of Audio-recordings was done in verbatim and analysed using content analysis technique.

\section{Findings}

All the doctors agree that Dyscalculia is neurological and developmental disorder who have problem understanding numbers or arithmetic. They are not mentally disabled. All Dyscalculia or specific learning-disabled children have right to be in mainstream education like any other normal children. like any other normal children.

Most of the doctors mentioned that Dyscalculia comes together with Dyslexia. That is why the test should include both Dyslexia and Dyscalculia. Symptoms includes difficulty in understanding numbers, falling behind in academic performance in math, Understanding and reading numbers, 
Counting money or days, difficulty in understanding co-ordination or direction.

However, there are different opinions regarding math difficulty and dyscalculia. Two doctors We interviewed believe Dyscalculia and Math difficulty are completely different thing. According to them, only those who has problem in number comprehension is considered as Dyscalculia. The reason there is different opinion is mainly because the way each specialist looks at it. For example, a psychiatrist's concern is mental health and he or she focused on brain and behavior only while defining Dyscalculia. But when it comes to Teacher or education psychologist, they look at Dyscalculia based on academic performance and that is why the definition varies in each department.

All the doctors agree that Dyscalculia should be diagnosed as early as possible. However, some Doctors also mentioned that they need to take academic achievement into account, the ideal age should be standard 1 or standard 2 so we can have a clear understanding of the academic difficulty that the person is facing.

There is no standardized guideline yet for Dyscalculia in Malaysia even though it is necessary. The main reason is that doctors are extremely busy. To make this kind of standardized guideline, need to work with education department, and do not have that luxury of time.

There is no medicine for Dyscalculia and according to doctors, there will not be any medicine for Dyscalculia since medicine does not go to brain. They never get cured. They need to adjust with others by proper training. All the doctors agree that that Dyscalculia children need rehabilitation and their problem need to be addressed in academy. Sending them to special education school is not a solution as it affects the children mentally. Computer games may help them to improve, but it is not a silver bullet solution. They need one to one intervention from teachers.

The requirements that have been given by doctors for Dyscalculia diagnosis are:

1) Patient's birth and family history (database)

2) Monitoring them by computer while they are taking test

3) Reading and writing test

4) IQ test

5) Academic performance history

6) Arithmetic test

7) Co-ordination test.

All the doctors agree that a standard policy is a very good step to take care of Dyscalculia children. Yet some doctors who believe Dyscalculia is a rare disease mentioned that the policy should standardized for Specific learning disability as a whole, not Dyscalculia alone.

\subsection{Dyscalculia Remedial Measures}

After carrying out an assessment, it is imperative that remediation follows immediately. This is because an accurate assessment of a child will determine the form of remediation to be used. Mathematics is an easy subject to teach (Emerson \& Babtie, 2010). It involves an analysis of the topic to be taught and identifying a child's firm ground. After this, one can proceed forward from there. Even with mathematics being a very easy subject to teach, the main difficulty comes in carrying out an assessment of children with any learning disability. However, it should be noted that any remediation process should be preceded by a careful assessment. In the previous years, teachers have relied on a multisensory instruction paired with the use of games in an attempt to help children learn and assimilate more. This is especially done in children experiencing mathematics anxiety. The use of games when learning math act as a guide, which takes away the feeling of learning mathematics and giving the child ample time to experience wins. Wins in children experiencing learning difficulties help increase a child's self-efficacy through positive verbal feedback and experiences. The games used can be categorised into two: Real games or math computer exercises or games with each having its own set of advantages and disadvantages. The advantage of using real games such as dominoes allow social interaction, which induces multi-sensory experience. When playing dominoes, children can decide on which level to play with the basic level helping them match canonical patterns-for example, matching 
the word 'five' to five dots. Maths computer games, on the other hand, can be very motivating to a child provided that the set level does not prove to be too easy or too hard, enabling him or her focus on a specific skill. However, in most cases, computer games tend to be too hard or present difficulties in dyscalculic children. Additionally, there are only a handful of computers games whose focus is mainly on extending comprehension of a subject compared to perfecting a skill (Williams,2013).

This puts Malaysian children at a disadvantage as the required resources and interventions for dealing with Dyscalculia are limited. (Arffin et al.,2017) experimented the effectiveness of mobile app named "Calculic Kids" on Dyscalculia children and found a positive result. Yet the problem with the experiment was that the participants were collected from Persatuan Dyslexia Malaysia and no Dyscalculia screening was conducted to confirm if they fit into the category of Dyscalculia.( Fiqa,2018) proposed a mobile app design model for the intervention of dyscalculia children name 'Calculic Model' based on practitioner's interviews for in order to support learning for Dyscalculia children. Yet no empirical data is available to measure its efficiency for Malaysian Dyscalculia Children. Kaur et al., (2018) proposed "i-Matematik" conceptual model based on a cognitive and conceptual theory which has been implemented in web-based courseware. However, both models are yet to be tested in real-life Dyscalculia scenario in Malaysia. Moreover, studies detailing interviews done on Malaysian teachers record $80 \%$ of complaints regarding the frequent lack of technical support and the lack of availability of ICT based resources for children.

Additionally, the teachers stated being overworked and disorganised as the tasks and materials given to them keep varying. In regard to the emergence and utilisation of web-based education such as Graphogame Math, Number Race, Dots2Track, Dots2Digit games have been experimented on Dyscalculia Children and achieved significant improvement of mathematical skills improvement among Dysalculia Children. However, data drawn from the teachers' interviews show a contradictory argument with about $60 \%$ of all teachers stating that there exist certain barriers when using technological based learning approaches such as weak internet and access to web services and the internet and the constant breakdowns of these systems (Keong et al.,2016).

Early detection methods will also come a long way on helping the fight against Dyscalculia. For example, Mazeyanti et al. record success when using the CheckDysc mobile game in identifying children with Dyscalculia. The parents and teachers of such students, mainly those in pre-school, might be unaware that the student is Dyscalculic. However, the use of mobile game apps such as CheckDysc has managed to provide an early detection system that can alert both parents and teachers, which will be prompted to institute the best remedial measures.

For example, the study done in Sabah, Malaysia reported that by using a computer-based Dyscalculia screener, they were able to discover that about $5.5 \%$ of all students were suffering from Dyscalculia. The screener would examine the student's response time and accuracy to test items. From the success recorded in this study, it would be helpful if such measures are implemented across all primary schools across Malaysia. This will ensure that such students are identified and corrective remedies and measures instituted at an early stage. With a number of researches showing the existence of a significant percentage of Dyscalculic students in any primary school setting, it should not be ignored.

Teachers and care providers should be trained to adopt a more lenient approach that is supportive and understanding of Dyscalculic students rather than terming them as lazy or stupid. A number of studies have suggested the training of teachers to integrate pictorial presentations and concrete materials in teaching abstract concepts such as number lines and place values. The teaching method should then gradually shift to abstract representations. However, one of the key challenges faced in Malaysia today is the lack of proper Dyscalculia knowledge and sensitisation. Teachers and educators have to have knowledge of Dyscalculia to help with identifying the affected students and working towards developing a teaching technique that will suit the Dyscalculic students. Previous studies have shown that only a fraction of the teachers believe they can identify the signs of Dyscalculia while the majority remain unaware of what it is. Additionally, others have denoted that teachers who have knowledge of this condition remain insecure while dealing with it due to limited information. The 
government should work to ensure that teachers encounter Dyscalculia during training. This will help increase the level of awareness among teachers and educators about Dyscalculia.

Augmented Reality remains an untapped potential as remediation of Dyscalculia. The use of AR technology helps enhance the visual perception of learners with Dyscalculia, thereby enriching the real world. The use of AR on Dyscalculia learners has the potential of improving their creativity, accessibility, smooth integration with others and boosted attention and motivation. Research has shown that AR provides immense benefits at a relatively low cost, making it an ideal remediation technique for Malaysian schools. Augmented Reality enhances both the teaching process and the learning process. Students get access to an increased level of elaboration from AR since it aids the integration of integration through a sensory elaboration using tactile, proprioceptive, verbal and visualspatial memory. AR increases the number of memory channels, which can be used to allow full encoding of the content, allowing for long-term retention.

\section{Conclusion}

This research is an attempt to find the causes, diagnosis and treatment of Dyscalculia in Malaysia from Clinician's perspective. For this purpose, interviews were held with doctors. It appears that Diagnosis of Dyscalculia need to address other learning disability in to account and class room intervention is the primary measure to take care of Dyscalculia children in Malaysia.

\section{Acknowledgment}

This research is fully funded by FRGS grant, (FRGS/1/2018/SSIog/UTP/o3/1). The authors fully acknowledged Ministry of Higher Education (MOHE) for the approved fund which makes this important research viable and effective.

We are also thankful to Ms Azlina Binti Lazim from the psychology and counselling service of Universiti Teknologi Petronas for helping us source potential interviewees.

\section{References}

Alarcon, M., DeFries, J. C., Gillis Light, J. \& Pennington, B. F. (1997). A twin study of mathematics disability. Journal of Learning Disabilities, 30, 617-623.

American Psychiatric Association. (2013). Diagnostic and statistical manual of mental disorders (4th ed.).

Ariffin, Mazeyanti \& Abd Halim, Fiqa Azureen \& Aziz, NorShakirah. (2017). Mobile Application for Dyscalculia Children in Malaysia.

Ariffin, Mazeyanti \& Abd Halim, Fiqa Azureen \& Savita, K S. (2018). The Features of Mobile App Design Model from Dyscalculia Children Personal Factor.

Ashkenazi, S., Rosenberg-Lee, M., Tenison, C. \& Menon, V. (2012). Weak task-related modulation and stimulus representations during arithmetic problem solving in children with developmental Dyscalculia. Developmental Cognitive Neuroscience, 2, 152-166.

Aster, M. v., Schweiter, M. \& Weinhold-Zulauf, M. (2007). Rechenstörungen bei Kindern: Vorläufer, Prävalenz und psychische Symptome. Zeitschrift für Entwicklungspsychologie und Pädagogische Psychologie, 39, 85-96.

Butterworth B (2002) Mathematics and the Brain. Opening address to the Mathematical Association. Reading: 15.

Butterworth, B. (2003). Dyscalculia screener. London: NFER-Nelson.

Butterworth, B. (2003). Dyscalculia screener. London: NFER-Nelson.

Butterworth, B. (2005). Developmental Dyscalculia. In J. Campbell (Ed.), The handbook of mathematical cognition (pp. 455-467). New York: Psychology Press.

Butterworth, B., \& Laurillard, D. (2010). Low numeracy and Dyscalculia: Identification and intervention. ZDM Mathematics Education, 42, 527-539.

Che Abdul Rani, Mohamad Firdaus \& Rohizan, Rizawati \& Abd Rahman, Nor. (2014). Web-based learning tool for primary school student with Dyscalculia.

Diwan, Piyush. (2008). Dyscalculia More Prevalent Than Dyslexia - A Report. Health News 
Dowker, A. (2005). Early identification and intervention for students with mathematic difficulties. Journal of Learning Disabilities, 38(4), 324-332.

Emerson, J., \& Babtie, P. (2010). The dyscalculia assessment. New York: Continuum.

Fu, Sai \& Chin, Kin Eng. (2017). An Online Survey Research Regarding Awareness of Dyscalculia among Educators in Sandakan District, Sabah. International Journal of Academic Research in Progressive Education and Development.

Gaupp, N., Zoelch, C. \& Schumann-Hengsteler, R. (2004). Defizite numerischer Basiskompetenzen bei rechenschwachen Kindern der 3. und 4. Klassenstufe. Zeitschrift für Pädagogische Psychologie, 18, 31-42.

Geary DC (2004) Mathematics and learning disabilities. Journal of Learning Disabilities; 37: 1, 4-15.

Geary DC, Bailey DH, Hoard MK. Predicting mathematical achievement and mathematical learning disability with a simple screening tool: The Number Sets Test. Journal of Psychoeducational Assessment 2009;27

Gifford, S. (2006). Dyscalculia: Myths and models. Research in Mathematics Education, 8(1),35-51.

Gillum, James. (2012). Dyscalculia: Issues for practice in educational psychology. Educational Psychology in Practice. 28. 1-11.

Hannell, Glynis. (2005). Dyscalculia: Action Plans for successful learning in Mathematics. New York: David Fulton Publishers.

Jordan, N.C., Glutting, J., Ramineni, C., \& Watkins, M.W. (2010). Validating a number sense screening tool for use in kindergarten and first grade: Prediction of mathematics proficiency in third grade. School Psychology Review, 39(2), 181-195.

Kaufmann, L., \& von Aster, M. (2012). The diagnosis and management of dyscalculia. Deutsches Arzteblatt international, $109(45), 767-778$.

Kaur, Jasber \& Abdul Majid, Rogayah \& Wahab, Noorafini. (2018). Adaptive Web-Based Learning Courseware for Students with Dyscalculia: 5th International Conference, i-USEr 2018, Puchong, Malaysia, August 28-30, 2018.

Keong, Wong \& Pang, Vincent \& Chin, Kin Eng \& Keong, Tan. (2016). Prevalence Rate of Dyscalculia According to Gender and School Location in Sabah, Malaysia.

Kucian, K., \& von Aster, M. (2015). Developmental Dyscalculia. European Journal of Pediatrics, 1-13.

Kucian, K., Loenneker, T., Dietrich, T., Dosch, M., Martin, E. \& Aster,M. v. (2006). Impaired neural networks for approximate calculation in dyscalculia children: A functional MRI study. Behavioral and Brain Functions, 2, 31.

Landerl, K., Bevan, A., \& Butterworth, B. (2004). Developmental Dyscalculia and basic numerical capacities: A study of 8-9-year-old students. Cognition, 93, 99-125.

Landerl, K., Bevan, A., \& Butterworth, B. (2004). Developmental Dyscalculia and basic numerical capacities: A study of 8-9-year-old students. Cognition, 93, 99-125.

Learning Support Services. (2015). Dyscalculia and specific difficulties in mathematics-guidance document.

Miundy, Kohilah \& Badioze Zaman, Halimah \& Nosrdin, Aliimran \& Ng, Kher. (2019). Evaluation of Visual Based Augmented Reality (AR) Learning Application (V-ARA-Dculia) for Dyscalculia Learners. JOIV: International

Orly, Rubinsten., \& Avishai, Henik. (2006). Double Dissociation of Functions in Developmental Dyslexia and Dyscalculia.

Petrill, S., Logan, J., Hart, S., Vincent, P., Thompson, L., Kovas, Y. \& Plomin, R. (2012). Math fluency is etiologically distinct from untimed math performance, decoding fluency, and untimed reading performance: Evidence from a twin study. Journal of Learning Disabilities, 45, 371-381.

Ramaa, S., \& Gowramma, I. P. (2002). A systematic procedure for identifying and classifying children with Dyscalculia among primary school school. Dyslexia, 8, 67-85.

S. N. Saidah Sarpudin and S. Zambri, "Web readability for students with Dyslexia: Malaysian case study," 2014 3rd International Conference on UserScience and Engineering (i-USEr), Shah Alam, 2014, pp. 192-197.

Shalev, R.S., Manor, O., Kerem, B., Ayali, M., Badichi, N., Friedlander, Y. et al. (2001). Developmental Dyscalculia is a family learning disability. Journal of Learning Disabilities, 34, 59-65.

Shalev, RS, \& von Aster, MG (2008). Identification, classification and prevalence ofdevelopmental dyscalculia. Encycopaedia of Language and Literacy Development.

Sigmundsson, Hermundur \& Anholt, SK \& Talcott, Joel. (2009). Are poor mathematics skills associated with visual deficits in temporal processing? Neuroscience letters. 469. 248-50.

Soares, N., Evans, T., \& Patel, D. R. (2018). Specific learning disability in mathematics: a comprehensive review. Translational pediatrics, $7(1), 48-62$.

von Aster, M., Dellatolas, G. (2006). ZAREKI-R : Batterie pour l'évaluation du traitement des nombres et du calcul chez l'enfant. [ZAREKI-R: Calculation and number processing assessment battery for children]. Paris, France: ECPA.

Wei, Q., Dong, H., Wang, J., \& Li, S. (2019). Interventions of Children with Developmental Dyscalculia. 
Willburger, Edith., Fusseneger, Barbara., Moll, Kristina., Wood, Guilherme., \& Landerl, Karin. (20o8). Naming speed in Dyslexia and Dyscalculia.

Williams, Ann. (2013). A teacher's perspective of Dyscalculia: Who counts? An interdisciplinary overview. Australian Journal of Learning Difficulties.

Wong. K.K., Pang, V., Chin. K.E, Tan, C. K., Lee, K. W.,Lay, Y. F. (2014).A Preliminary Study for Dyscalculia in Sabah,Malaysia. 7th International Conference on Education in Mathematics, Science and Technology (ICEMST 2014) Proceedings, 462- 469.

World Health Organization (WHO). (2011). WHO classifications F81.2 Specific disorder of Arithmetic skills. Retrieved May 3,2020, from http://who.int/classifications/icd/en/bluebook.pdf

Zulkifli, N.S., Kamal, N.F., My, \& Othman, M.F. (2012). A Review: Fundamental and Applications of functional Magnetic Resonance Imaging (fMRI) on brain learning activities. 